\title{
COMPARATIVE STUDY OF TWO COGENERATION SYSTEMS BASED ON ENERGY RECOVERY OF FUMES FROM A CASTING PROCESS
}

\author{
M. Fernández*, C J Renedo*, J. García**, S. Pérez*, I. Fernández*, M. Mañana* \\ *Department of electrical and energy engineering of the University of Cantabria \\ Av Los Castros s/n, Santander, Cantabria \\ renedoc@unican.es \\ ** NISSAN MOTOR IBERICA, S.A. \\ Av Jose Ma Quijano No22, Los Corrales de Buelna, Cantabria
}

\begin{abstract}
This paper develops the comparison of two cogeneration systems that are suitable to perform heat energy recovery of the smoke produced by a casting process.
\end{abstract}

Keywords:

Heat recovery, heating, cogeneration, rentability,

\section{Introduction}

The industry sector has great potential in taking advantage of fumes from waste heat in order to produced heat and power, and thereby to provide dramatic cost, energy, economic and environmental benefits.

\section{Case Study}

The case studies are intended to recover energy from smoke from a foundry cupola. It is intended to achieve the following objectives:

- To produce electricity, which will allow to obtain economic benefits. This is true whether the energy is consumed in the plant or it is sold to the power company. Both alternatives will be studied, deciding in favor of the more profitable, which will determined by the price of purchase/sale of $\mathrm{kWh}$.

- To generate hot water for heating the factory and the other units. This will result in greater comfort in the facilities for workers.
- To reduce the overall amount of $\mathrm{CO}_{2}$ that is emitted into the atmosphere, by carrying out the reuse of the fumes of the cupola. This will reduce, to some extent, the harmful effect that fumes causes on the atmosphere.

\subsection{Data of the plant}

The flow and temperature of the output gas were obtained from computers that are responsible for controlling the melting process in the cupola furnace. The flow is the sum of flows entering the burner (air, natural gas).

- Air flow + CO from the cupola (air suction)

- Natural gas flow

- Combustion air flow

- Burner combustion air flow

- Cooling air flow

The outlet temperature is obtained from the measuring sensor placed at the exit of the exchanger. Figures 1 and 2 show the flow and temperature evolution of the smoke output over an entire cast, for different days of the production process. These fumes have an average flow of $17,000 \mathrm{Nm}^{3} / \mathrm{h}$ at $620^{\circ} \mathrm{C}$.

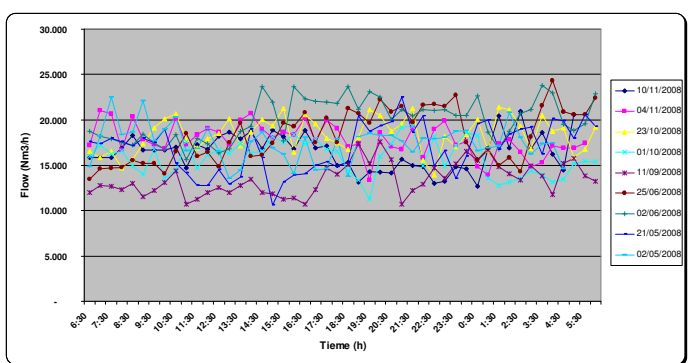

Figure 1.- Evolution of the smoke flow for different cast 


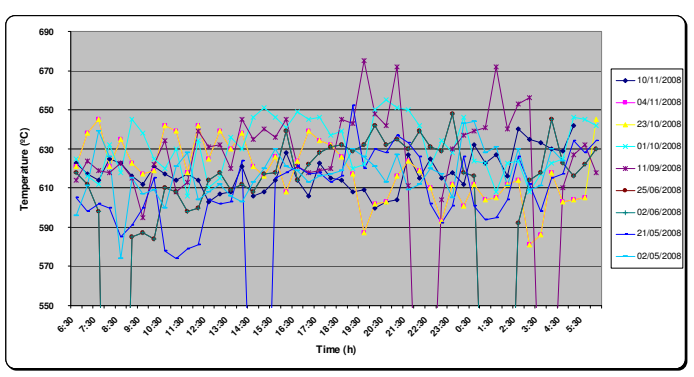

Figure 2 .- Evolution of the smoke temperature for different cast.

A gas analyzer placed at the exit of smoke gives the same composition. Table 1 gives the average composition of the fumes.

Table 1 .- Composition of exhaust fumes

\begin{tabular}{|c|c|}
\hline Estimated gas composition & Volume (\%) \\
\hline $\mathrm{N}_{2}$ & 78 \\
\hline $\mathrm{O}_{2}$ & 10 \\
\hline $\mathrm{CO}_{2}$ & 10 \\
\hline $\mathrm{H}_{2} \mathrm{O}$ & 2 \\
\hline
\end{tabular}

Figure 3 shows the SCADA for data acquisition.

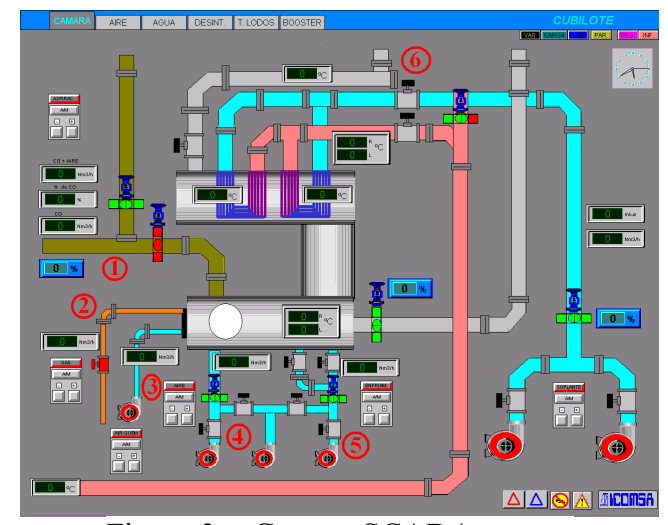

Figure 3 .- Current SCADA system

\section{Alternatives considered}

The study considers two alternatives for the main cogeneration system.

- The alternative $\mathrm{N}^{\mathrm{o}} 1$ considers the installation of modules FREE POWER FP120. It is a system producing electricity and hot water. It is a compact equipment which includes the main elements of a cogeneration system (turbine, generator, condenser, ...) and is capable of providing $130 \mathrm{~kW}$ of electrical power and $612 \mathrm{~kW}$ heat at $65^{\circ} \mathrm{C}$.

- Alternative $\mathrm{N}^{\mathrm{o}} 2$ considers the design of a classical plant with steam turbine and all other necessary components. This option has a higher flexibility and versatility in terms of installed capacity and heating water temperature.

It also examines two alternatives concerning the cooling condenser:

- Dry tower

- Wet tower

And two more for the heating system of the factory buildings:

- By air curtains

- Through fan coils

\section{Operational analysis}

This section performs the functional analysis of the two alternatives considered.

\subsection{Equipment FP120}

Alternative 1 is simple in design because the heat of the fumes is transferred directly to the FP120, which is able to produce electricity and generate hot water for subsequent heating, simultaneously. The equipment only requires a space where it can be located.

The FP120 is composed of the following elements: turbine, alternator, electrical box, disc rupture, expansion tank, recuperator, condenser, heat exchanger, oil pump and electrical outlets, and works according to the schedule shown in Figure 4.

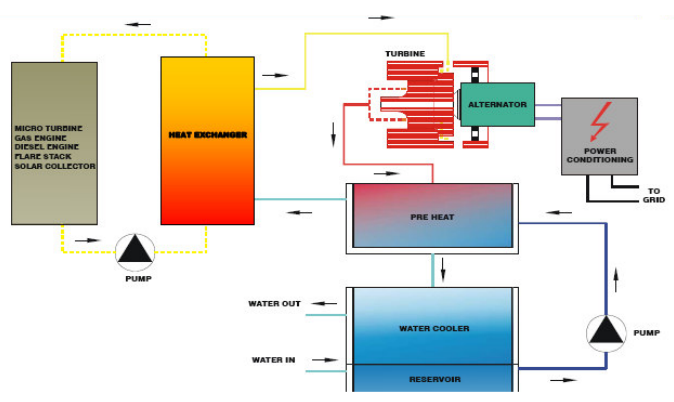

Figure 4.- Working sequence of the FP120

The operation sequence of the FP120 is based on the heat removal from an industrial source, in this case from the cupola smoke, and later on the transfer to the thermal oil. After heating the thermal oil, water circulating in closed circuit is heated, generating the steam that will be used in the microturbine and that is coupled to a compact generator to produce electric power. The rest of the energy is used in a hot water circuit for heating, the temperature of this heating water is $65^{\circ} \mathrm{C}$. 


\subsection{Classical design}

Alternative 2 is the classic design of such facilities, where the electricity is produced by means of a turbine, the steam being generated by a boiler, in this case recovery boiler. The required elements are shown in Figure 5.

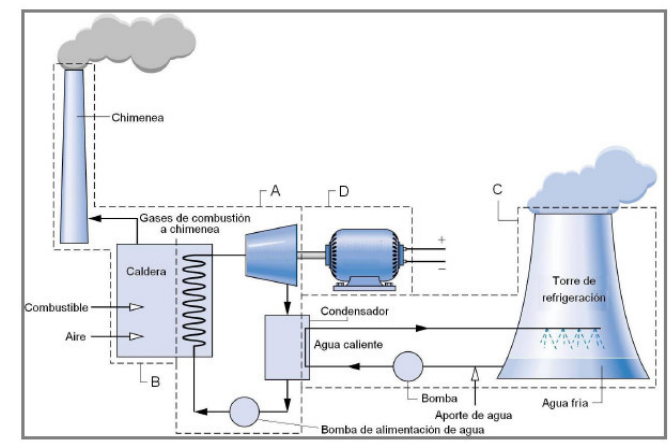

Figure 5.- Schematic diagram of the installation

The operation begins driving the exhaust fumes to a recovery boiler which produces steam. The steam enters the turbine where it expands, transforming part of its heat energy into mechanical energy. The cycle is completed through the condenser, which liquefies the wet steam from the turbine to return later to the boiler.

If the energy source is know, the production of steam in the boiler could be determined. The steam is generated at a pressure of 20 bar and go out at a temperature of $400{ }^{\circ} \mathrm{C}$, obtaining a steam mass flow $3.700 \mathrm{~kg} / \mathrm{ha}$ at the output. These are the best working conditions that can be obtained, starting from the available fumes.

\section{Energy analysis}

The power available depends on the flow and on the change of temperature obtained from the fumes. This is approximately $3,000 \mathrm{~kW}$.

$$
E=\text { Flow } \times \rho \times c_{p} \times \Delta T
$$

\subsection{Equipment FP120}

In order to get the maximum performance from the system with the alternative 1, the power of this device should be known. Each FP120 needs $742.2 \mathrm{kWth}$, and provides $612 \mathrm{~kW}$ th and 130 $\mathrm{kWe}$. Therefore, four equipments will be necessary. This configuration provides $520 \mathrm{kWe}$ of electrical power and 2,448 $\mathrm{kW}$ th of thermal power at $65^{\circ} \mathrm{C}$. These amounts will remain constant throughout the annual period, provided that the cupola is working.

The electrical performance of the cycle will be:

$$
\eta_{\text {electric }}=\frac{P_{\text {electric }}}{Q_{\text {absorbed }}}=\frac{520 \mathrm{~kW}}{2,995 \mathrm{~kW}}=0.17
$$

These amounts remain constant over the annual period, provided that the cupola works, the power generation being unable to increase in periods in which there is no thermal demand of space heating.

\subsection{Classical design}

The design of this alternative should meet the thermal demand during the heating period, and should maximize the electricity production when there is no heating demand.

\subsubsection{Period without heating}

This is used at times of the year when there is no space heating demands, so that what we are trying to do is maximize the production of electricity. This duty cycle is shown in Figure 6.

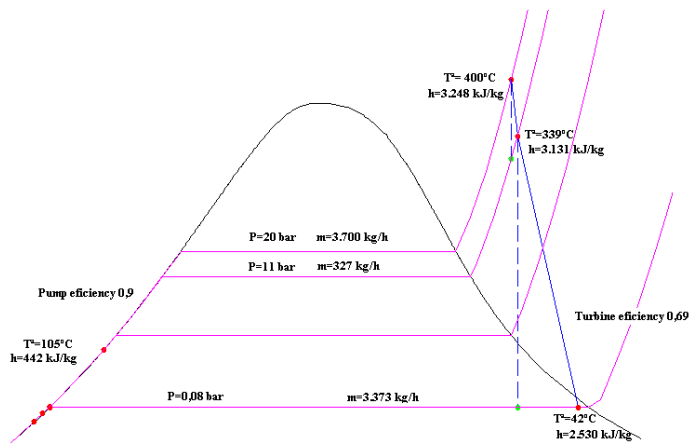

Figure 6.- Steam cycle for the situation where no heating is used.

The total power that can be obtained in this situation is:

$$
P_{\text {total }}=\dot{m} \times\left(h_{\text {out boiler }}-h_{\text {in boiler }}\right)=2,884 \mathrm{~kW}
$$

The power to obtain from the turbine will be:

$$
P_{\text {turbine }}=\dot{m} \times\left(h_{\text {in turb }}-h_{\text {out turb }}\right)=683 \mathrm{~kW}
$$

Therefore, the electrical power will be affected by the performance of the generator.

$$
P_{\text {electric }}=\eta_{\text {gen }} \times P_{\text {turb }}=0,96 \times 683=655 \mathrm{~kW}
$$

The thermal power will be completely dissipated by the auxiliary cooling system:

$$
P_{\text {th cooling }}=P_{\text {total }}-P_{\text {turb }}=2,201 \mathrm{~kW}
$$

The efficiency of the electricity production will be: 


$$
\eta_{\text {electric }}=\frac{P_{\text {electric }}}{Q_{\text {absorbed }}}=\frac{655 \mathrm{~kW}}{2,884 \mathrm{~kW}}=0.23
$$

\subsubsection{Period with heating}

This is used at times of the year when space heating is demanded, so that in this situation what the heating demands are met, trying to maintain maximum electricity production. This cycle of work will be shown in Figure 7.

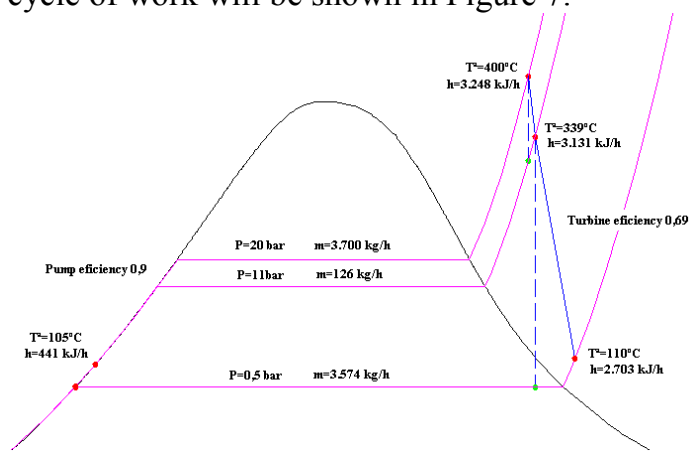

Figure 7.- Steam cycle for the situation in which heat is used.

The total power that can be obtained in this situation is the same that in the previous situation, $2.884 \mathrm{~kW}$.

The power obtained in the turbine will be:

$$
P_{\text {turbine }}=\dot{m} \times\left(h_{\text {in turb }}-h_{\text {out turb }}\right)=545 \mathrm{~kW}
$$

Therefore, the electrical power will be affected by the performance of the generator.

$$
P_{\text {electric }}=\eta_{\text {gen }} \times P_{\text {turb }}=0,96 \times 545=523 \mathrm{~kW}
$$

The efficiency in electricity production will be:

$$
\eta_{\text {electric }}=\frac{P_{\text {electric }}}{Q_{\text {absorbed }}}=\frac{523 \mathrm{~kW}}{2,884 \mathrm{~kW}}=0.18
$$

The thermal power will be dissipated by the heating system and will be:

$$
P_{\text {th cooling }}=P_{\text {total }}-P_{\text {turb }}=2,339 \mathrm{~kW}
$$

The water will be circulated at the entrance of the condenser at a temperature of $70^{\circ} \mathrm{C}$ and at the output at about $90^{\circ} \mathrm{C}$, taking advantage of it through a heat exchanger for the heating circuit. Figure 8 shows a schematic representation of both circuits.

With the desired temperatures in the circuit and the thermal power available, the circulating water flow is:
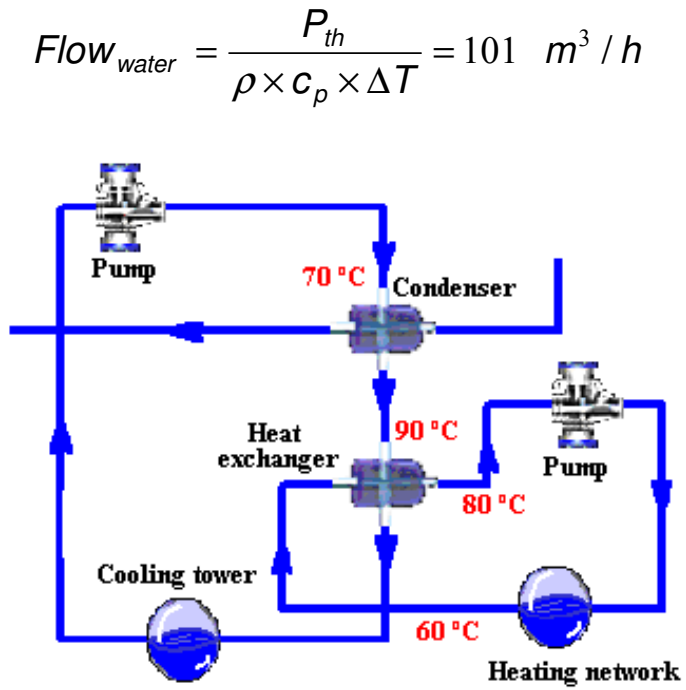

Figure 8.- Cooling circuits and heating systems.

With the desired temperatures in the circuit and the thermal power available, the circulating water flow is:

$$
\text { Flow }_{\text {water }}=\frac{P_{\text {th }}}{\rho \times c_{p} \times \Delta T}=101 \mathrm{~m}^{3} / \mathrm{h}
$$

The same flow rate will circulate by the heating circuit than by the cooling circuit. Also, the heat exchanger allows water for the heating circuit to be obtained at $80^{\circ} \mathrm{C}$, as shown in Figure 11.

\subsection{Alternative cooling and heating}

This section discusses alternatives for auxiliary cooling and heating. Both alternatives are independent of the cogeneration system.

\subsubsection{Cooling System}

The refrigeration system used must be able to dissipate a thermal power of $2,400 \mathrm{~kW}$. For this dry or wet tower systems can be used.

Dry tower systems remove less power than the wet tower systems, so that greater number of devices are needed. This increases the surface requirements.

When heating is required, the surplus heat will be almost dissipated by the heating circuit. In this situation the cooling system will not work in practice. When you do not need space heating, cooling system dissipate all the previous thermal power.

Once the thermal power dissipated by the system and the two types of cooling system that can be used are known, it is necessary to define the configuration that dissipates the heat. For 
this, a balance between the following features should be found:

- The cooling requirements of the process

- The local constraints (including legal status)

- Environmental requirements

So both options are valid, and the selection criterion is the economic one.

\subsubsection{Heating equipment}

\section{Air curtains}

Air curtains create an air barrier that prevents very effectively the entry of cold air flow and provides a warm indoor environment. This should be placed on doors and openings, trying to make the building as hermetic as possible and that heat stays inside. They allow the use of all floor space, even in front the door.

The proper functioning of the curtain depends heavily on a good fit for the curtain to the hole that is on the building, so the aim is to completely close the openings.

The installation will require 24 air curtains with 52 total meters, so perfectly cover the gap of the door.

Calculations have been made to $15^{\circ} \mathrm{C}$ air temperature of the building. In Table 2 we have the maximum working situation.

Table 2.- Maximum values with the air curtains are going to work

\begin{tabular}{|c|c|c|c|}
\hline Door & $\begin{array}{c}\text { Air flow } \\
\left(\mathrm{m}^{3} / \mathrm{h}\right)\end{array}$ & $\begin{array}{c}\text { Power } \\
(\mathrm{kW})\end{array}$ & $\begin{array}{c}\text { Water flow } \\
(1 / \mathrm{s})\end{array}$ \\
\hline 1 & 21,000 & 173.5 & 2.12 \\
\hline 2 & 28,000 & 232.7 & 2.85 \\
\hline 3 & 21,000 & 173.5 & 2.12 \\
\hline 4 & 21,000 & 173.5 & 2.12 \\
\hline 5 & 35,000 & 288.3 & 3.53 \\
\hline 6 & 17,500 & 147.1 & 1.8 \\
\hline 7 & 17,500 & 147.1 & 1.8 \\
\hline 8 & 24,500 & 203.5 & 2.49 \\
\hline 9 & 21,000 & 173.5 & 2.12 \\
\hline 10 & 21,000 & 173.5 & 2.12 \\
\hline 11 & 17,500 & 147.1 & 1.8 \\
\hline 12 & 17,500 & 147.1 & 1.8 \\
\hline \multirow[t]{2}{*}{13} & 38,500 & 320.6 & 3.92 \\
\hline & TOTAL & 2,501 & 30.59 \\
\hline
\end{tabular}

The maximum working situation requires a slightly higher flow to that available for the heating circuit, so it may dissipate all the energy of the condenser.

\section{Fancoils}

The placement of the fan heaters will be held at strategic points in the building, primarily in areas near doors where there may be air flows, trying to make the facility as hermetic as possible.

In this case it is not necessary to know the length of the doors, but only strategic points of the plant. They will be placed near the doors or next to the air streams. Therefore, it will be needed exactly 32 units. The data are provided in Table 3.

Tabla 3.- Valores máximos para los fancoils

\begin{tabular}{|c|c|c|c|}
\hline $\begin{array}{c}\text { Fan } \\
\text { Speed }\end{array}$ & $\begin{array}{c}\text { Power } \\
(\mathrm{kW})\end{array}$ & $\begin{array}{c}\text { Water flor } \\
(\mathrm{l} / \mathrm{s})\end{array}$ & $\begin{array}{c}\text { Air flor } \\
\left(\mathrm{m}^{3} / \mathrm{h}\right)\end{array}$ \\
\hline 5 & 2,672 & 31.68 & 182,720 \\
\hline 4 & 2,342 & 27.84 & 149,760 \\
\hline 3 & 1,792 & 21.12 & 101,440 \\
\hline 2 & 1,408 & 16.64 & 72,320 \\
\hline
\end{tabular}

In the maximum working situation there is a greater circulation flow than that available in the heating circuit and therefore, it can dissipate more energy. Thus, the energy obtained after the heat exchange can be dissipated without any kind of problem, using the heating circuit.

\section{Economics analysis}

The economic analysis focused on:

- To get the cost of equipment and facilities of the two alternatives.

- To obtain the necessary investment in order to implement each one of the alternatives

- To get the incomes of each alternative

Additionally, it performs the technical and the economic analysis of each one of the alternatives.

\subsection{Cost of investment in equipment and facilities}

\section{Equipment FP120}

In the alternative with this equipment, only the cost should be considering. The cost of a module is $280,000 €$, and you need 4 modules. This cost must be added to the costs incurred by the equipment that is common to both alternatives and that will be showed later.

\section{Classical alternative}

It should consider the costs incurred by the boiler for gas recovery and by the turbogroup. 
- The steam boiler is pirotubular, designed especially for the use of recovery gas. The equipment cost is $€ 280,000$.

- The steam turbogroup is condensation based and has 2 axial stages. The total equipment cost is $€ 960,000$.

This option has a cost of $1,240,000 €$. To this cost, it must be added that of the devices that are common with the previous alternative.

\section{Equipment and facilities common to both alternatives}

The equipment common to both alternatives are:

- Large diameter pipe for exhaust fumes. The total cost is $200,000 €$.

- Conditioning of the room to locate the main devices. This is about $21,000 €$.

- Electrical facility. The total cost is $€$ 26,000.

- Hydraulic cooling circuit. The total cost is $16,000 €$

- Cooling system. As mentioned above there are two alternatives.

○ Wet tower, $36.500 €$.

- Dry tower, $177.000 €$.

Since from the points of view functional and energy, both systems behave in the same way, the economic approach is essential to choose the wet tower.

- Heating circuit. The total cost is 100,000 $€$

- Heating equipment. As mentioned above there are two alternatives:

- Air curtains. The overall cost of the curtains is $200,000 €$.

- Fancoils. The cost of 32 units, with its accessories is $96,000 €$.

Since from the points of view functional and energy, both systems behave in the same way, the economic approach is essential to choose the fancoils.

Table 4 shows the investment to be made for each of the two alternatives.

Table 4 .- Investments made in each alternative.

\begin{tabular}{|c|c|c|}
\hline Alternative & $\begin{array}{c}\text { Total cost }(€) \\
\text { excluding VAT. }\end{array}$ & $\begin{array}{c}\text { Total cost }(€) \\
\text { including VAT. }\end{array}$ \\
\hline FP120 & $1,575,500$ & $1,827,600$ \\
\hline Clasical & $1,735,500$ & $2,013,000$ \\
\hline
\end{tabular}

\subsection{Revenue}

The factory runs three shifts, i.e. 24 hours a day for about 280 days of production; therefore the installation will run for 6.720 hours. The current retail price of electricity is fixed at $0.0973 € / \mathrm{kWh}$.

The revenue to be derived from the sale of electricity during the production period will be:

\section{Modules FP120}

Production is unchanged throughout the period of plant operation. Annual revenues are:

\section{Classical system}

One must distinguish between the period in which the heater is used (3,360 hours) and the period of time when it is not in use $(3,360$ hours). The income obtained will be:

$$
\text { Revenue }=340,000 €
$$

\subsection{Cost of operation}

Maintenance costs, labour and energy costs (consumption of pumps, fans of tower and air heaters), have to be considered.

\section{Equipment FP120}

Operating costs that arise after implementing this alternative are shown in Table 5.

Table 5 .- Annual operating costs $(€)$

\begin{tabular}{|l|c|}
\hline \multicolumn{2}{|c|}{ Maintenance costs } \\
\cline { 1 - 1 } Equipment FP120 & 25,000 \\
\hline Other equipment & 5,000 \\
\hline Labour costs & 30,000 \\
\hline \multicolumn{1}{|c|}{ Energy costs } & 5,000 \\
\hline Fan heaters & 6,500 \\
\hline Cooling tower fans & 9,000 \\
\hline Pump consumption & 80,500 \\
\hline \multicolumn{2}{|c|}{ TOTAL PER YEAR }
\end{tabular}

\section{Classical system}

Operating costs that arise after implementing this alternative are shown in Table 6.

Table 6 .- Annual operating costs $(€)$

\begin{tabular}{|c|c|}
\hline Maintenance costs & \\
\hline Boiler & 10,500 \\
\hline Turbine & 17,000 \\
\hline Other equipment & 5,000 \\
\hline Labour costs & 30,000 \\
\hline \multicolumn{2}{|l|}{ Energy costs } \\
\hline Fan heaters & 5,000 \\
\hline Cooling tower fans & 6,500 \\
\hline Pump consumption & 9,000 \\
\hline TOTAL PER YEAR & 83,000 \\
\hline
\end{tabular}




\subsection{Profitability analysis}

Once the initial investment in equipment, the annual revenues and the operating costs, are known, it is possible to calculate the internal rate of return for each of the alternatives. Figure 9 shows the evolution of this parameter, depending on the available refresh rate.

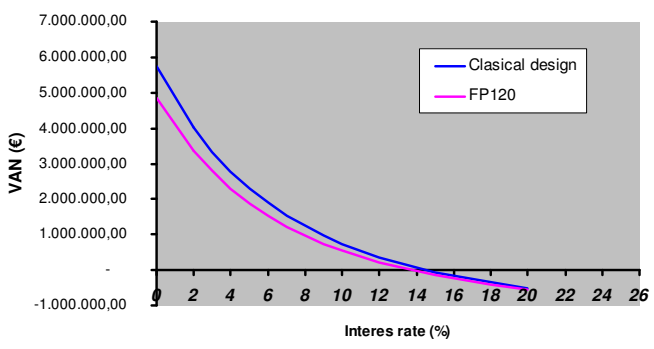

Figure 9.- Internal return rate for each of the alternatives.

The lifespan of both installation options is set at 25 years. The alternative with the FP 120 modules will be profitable until a refresh rate of $13 \%$, while the classical alternative is profitable until a refresh rate of $14.5 \%$. For the current rate that is fixed at around $3 \%$, the classical alternative is more profitable because you get a higher internal rate of return. It is also remarkable that with a increasing refresh rate both alternatives tend to the balance, but that appears with interest rates much higher than today's.

\section{Conclusions}

After carrying out the functional, energy and economic analysis, the following conclusions are drawn for each of the alternatives.

\subsection{Advantages and disadvantages of FP120}

Among the most important advantages, compared to the classical system, one highlights the following:

- The unit is independent, not requiring any civil work.

- Minimum weight, which facilitates assembly and installation.

- Requires less space

- Assembly simpler and lower cost

- Lower initial investment

- Cleaner system

Among the disadvantages the following are presented:

- Less efficient system in producing electricity

- High maintenance costs, for using thermal oil

- Obtaining lower electric power
- Heat source at a lower temperature for heating equipment

- System recently introduced, so the operation of this technology is no guarantee

- Requires trained and specialized personnel due to the type of technology these modules carry.

- Reliability unknown, since they are prototypes in sale since 2009 and therefore, it does not know its duration and if its components will withstand the conditions demanded

\subsection{Advantages and disadvantages of classical design}

Among the advantages of this alternative the following should be highlighted:

- Overall efficiency very high

- Extremely safe

- Long service life, since it is a guaranteed and proven system

- Wide range of power, which allows variations in terms of changes in the fumes

- Presents higher electrical efficiency

- Lower maintenance cost

Among the disadvantages the following are presented:

- Civil works required

- Mounting more complicated, so the cost is increased

- Requires more space, since it must comply with regulations

- Heavy equipment, so limiting their movement

- Higher cost

- Slow launch

\section{Acknowledgements}

The authors would like to thank the financial support of Government of Cantabria and NISSAN under the INVESNOVA research project and to the Council on Research and Technological Development of the University of Cantabria by their administrative assistance.

\section{References}

- NISSAN MOTOR IBÉRICA S.A.

- www.freepower.co.uk

- www.icogen-sa.com

- www.frico.se/spain

- www.siemens-home.es

- www.sulzercoolingtowers.com 